\title{
INVENTARISASI JENIS ANGGREK (ORCHIDACEAE) TERESTRIAL DI TAMAN WISATA ALAM BUKIT KELAM KABUPATEN SINTANG
}

\author{
Lulu Dwi Lestari ${ }^{1}$, Rafdinal $^{1}$, Mukarlina ${ }^{1}$ \\ ${ }^{1}$ Program Studi Biologi, Fakultas MIPA, Universitas Tanjungpura, \\ Jl. Prof. Dr. H. Hadari Nawawi, Pontianak \\ email korespondensi: lulud723@gmail.com
}

\begin{abstract}
Bukit Kelam Nature Tourism Park in Sintang District is a nature conservation area that has become the habitat for a wide range of endemic flora in West Kalimantan. This study aimed to identify terrrestrial orchids (Orchidaceae) species in Bukit Kelam Nature Tourism Park in Sintang District. This study was conducted from September to November 2017. The inventory of orchids specieswas done by the cruise method. The study obtained 12 terrestrial orchid species i.e Arundina graminifolia, Bromheadia finlaysoniana, Corybas pictus, Coelogyne kelamensis, Dendrobium lobii, Dendrobium olivaceum, Dipodium pictum, Liparis sp., Paphiopedilum bullenianum, Plocoglottis lowii, Spathoglottis kimbaliana, and Thrixspermumamplexicaule.
\end{abstract}

Keywords: Inventory, Orchids, Bukit Kelam Nature Tourism Park

\section{PENDAHULUAN}

Tumbuhan anggrek termasuk dalam famili Orchidaceae merupakan salah satu tumbuhan berbunga yang dapat tumbuh di berbagai habitat seperti tanah berhumus, tanah rawarawa, batu cadas, dan pohon. Anggrek salah satu tumbuhan yang kekayaan hayatinya dilindungi oleh undang-undang No. 5 tahun 1990 tentang Konservasi Sumber Daya Alam hayati dan satwa liar (Gunadi,1985). Anggrek memiliki jenis lebih banyak dibandingkan tumbuhan berbunga lainnya yang terdiri dari 850 genus dan 25000 spesies yang tersebar di seluruh dunia. Indonesia memiliki keanekaragaman anggrek sebanyak 5000 spesies dan salah satunya tersebar di Kalimantan sebanyak 2500-3000 spesies (Irawati, 2002).

Kawasan Bukit Kelam merupakan salah satu Taman Wisata Alam yang terdapat di Kabupaten Sintang. TWA Bukit Kelam adalah salah satu batu terbesar di dunia dan menjadi habitat berbagai jenis tumbuhan yang terletak di Kabupaten Sintang. Keunikan TWA Bukit Kelam lainnya yaitu terdapat tumbuhan endemik seperti kantong semar (Nepenthes clipeata) dan anggrek hitam (Coelogyn pandurata) yang hampir punah. TWA Bukit
Kelam termasuk lokasi yang diawasi oleh aktivitas yang dapat menyebabkan punahnya anggrek alam yaitu pengkoleksian dan penjualan anggrek liar secara tidak terkendali dan illegal yang dilakukan penggemar anggrek. Keunikan TWA Bukit Kelam dan kurangnya pengawasan dikawasan tersebut menjadikan penelitian tentang jenis anggrek terestrial di lokasi tersebut perlu dilakukan agar dapat dijadikan usaha konservasi serta pengelolaan yang tepat untuk kawasan TWA Bukit Kelam.

Tujuan dilakukannya penelitian ini adalah untuk mengetahui jenis-jenis tumbuhan anggrek terestrial di Kawasan Hutan Wisata Bukit Kelam Kabupaten Sintang.

\section{BAHAN DAN METODE}

Waktu dan Tempat Penelitian

Penelitian ini dilaksanakan pada bulan September-November 2017. Pengambilan sampel dilakukan di Taman Wisata Bukit Kelam Kabupaten Sintang. Identifikasi dan pembuatan kunci determinasi dilakukan di Laboratorium Biologi Fakultas Matematika dan Ilmu Pengetahuan Alam, Universitas Tanjungpura, Pontianak. 


\section{Bahan}

Bahan yang digunakan pada penelitian ini adalah alkohol $70 \%$.

\section{Deskripsi Umum Lokasi Penelitian}

Lokasi penelitian terletak di Dusun Kenukut, Desa Kebong, Kecamatan Kelam Permai, Kabupaten Sintang. Secara geografis kawasan

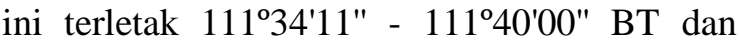
0005'25" - 0005'27" LS. Topografi kawasan TWA Bukit Kelam datar sampai berbukit dan didominasi oleh podsolid merah kuning. Berdasarkan keputusan Menteri Kehutanan No 594/Kpts-II/92 kawasan ini ditetapkan menjadi Taman Wisata Alam dengan luas $520 \mathrm{Ha}$ (BKSDA, 2010).

\section{Prosedur Kerja}

\section{Pengambilan sampel}

Pengambilan sampel dilakukan di TWA Bukit Kelam dengan menggunakan metode jelajah (Cruise Methode) dengan mengikuti jalur dan mengumpulkan setiap sampel yang ditemukan. Anggrek yang dijumpai didokumentasi, diambil dan diberi etiket gantung yang berisi keterangan mengenai nomor koleksi, nama ilmiah, nama daerah, habitat dan deskripsi singkat. Data yang diperoleh akan dianalisa secara deskriptif, yaitu dengan mendeskripsikan ciri morfologi dari setiap sampel tumbuhan anggrek yang ditemukan.

\section{Pembuatan Herbarium}

Tumbuhan anggrek yang diperoleh dikoleksi dengan membuat herbarium. Pembuatan herbarium kering dilakukan dengan beberapa tahapan, yaitu pengambilan sampel lengkap dari akar, batang, daun, biji dan bunga bila ditemukan, pengeringan dan penempelan sampel. Pengeringan sampel berupa akar, batang, daun yang telah diambil diberi label berisi keterangan mengenai tumbuhan anggrek dan diletakkan di atas kertas koran. Selanjutnya dilakukan penyemprotan menggunakan alkohol $70 \%$ hingga basah.

Sampel ditata dengan rapi diantara koran kering atau kertas karton dan diapit dengan penekan yang kemudian dikering anginkan di tempat yang terbuka hinggga sampel kering dan kaku (Tjitrosoepomo, 1998).

\section{Identifikasi}

Identifikasi dilakukan dengan melihat ciri morfologi yang meliputi warna, bentuk, ukuran dan ciri khusus pada anggrek. Tumbuhan anggrek yang ditemukan kemudian diidentifikasi dengan mencocokkan gambar dan deskripsi yang terdapat di dalam buku identifikasi hingga tingkat jenis. Identifikasi dilakukan dengan menggunakan pustaka Chan et.al., (1994), Cribb (1997), dan Siregar et.al., (2005).

\section{PEMBAHASAN}

\section{Hasil}

Berdasarkan hasil penelitian yang telah dilakukan di Taman Wisata Alam (TWA) Bukit Kelam Kabupaten Sintang, ditemukan 12 spesies anggrek terestrial yang terdiri atas Arundina graminifolia, Bromheadia finlaysoniana, Corybas pictus, Coelogyne kelamensis, Dendrobium lobii, Dendrobium olivaceum, Dipodium pictum, Liparis sp., Paphiopedilum bullenianum, Plocoglottis lowii, Spathoglottis kimballiana, Thrixspermum amplexicaule (Tabel 1)

Tabe 1. Jenis anggrek terestrial yang didapatkan di kawasan Taman Wisata Alam Bukit Kelam Kabupaten Sintang

\begin{tabular}{lll}
\hline No. & Genus & Spesies \\
\hline 1. & Arundina & Arundina graminifolia \\
2. & Bromheadia & Bromheadia finlaysoniana \\
3. & Corybas & Corybas pictus \\
4. & Coelogyne & Coelogyne kelamensis \\
5. & Dendrobium & Dendrobium lobii \\
& & Dendrobium olivaceum \\
6. & Dipodium & Dipodium pictum \\
7. & Liparis & Liparis sp. \\
8. & Paphiopedilum & Paphiopedilum bullenianum \\
9. & Plocoglottis & Plocoglottis lowii \\
10. & Spathoglottis & Spathoglottis kimballiana \\
11. & Thrixspermum & Thrixspermum amplexicaule \\
\hline & &
\end{tabular}




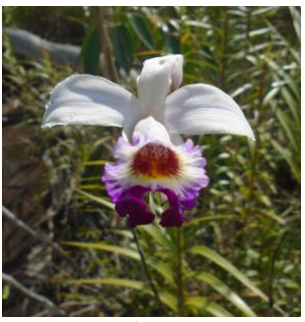

A

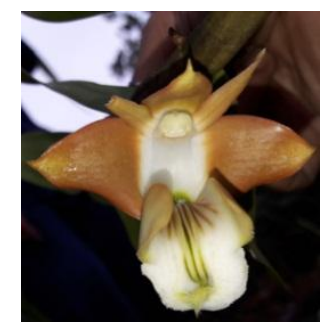

$\mathrm{F}$

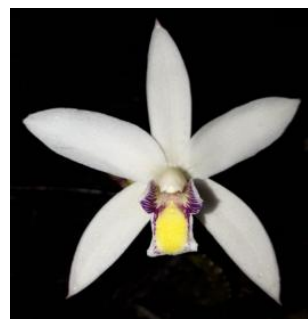

B

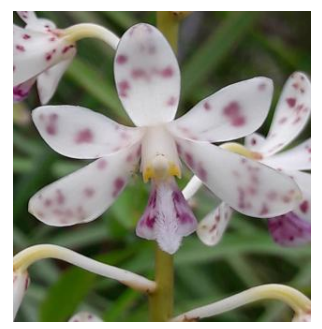

G

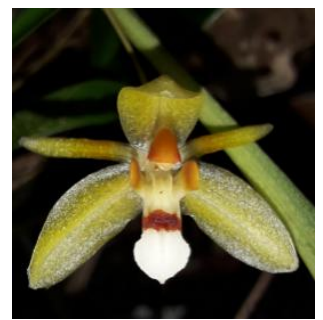

C

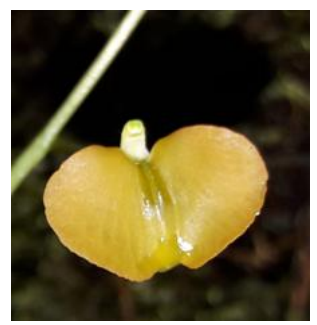

$\mathrm{H}$

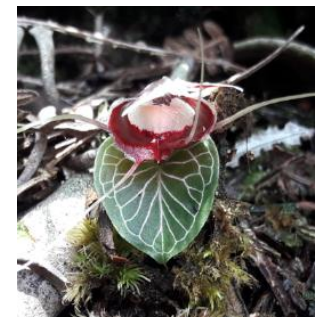

D

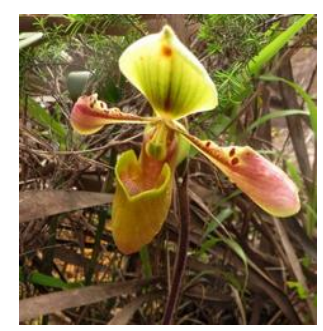

I

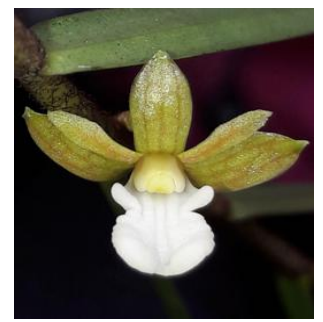

$\mathrm{E}$

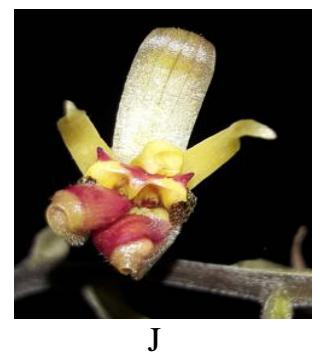

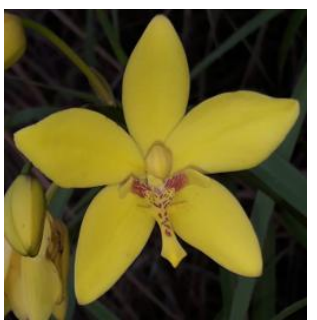

$\mathrm{K}$

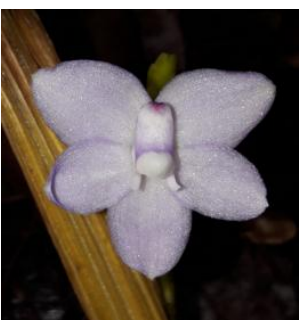

$\mathrm{L}$

Gambar 1. Jenis-jenis anggrek yang ditemukan di kawasan Taman Wisata Alam Bukit Kelam (A) Arundina graminifolia (B) Bromheadia finlaysoniana (C) Coelogyne kelamensis (D) Corybas pictus (E) Dendrobium Lobii (F) Dendrobium Olivaceum (G) Dipodium pictum (H) Liparis sp. (I) Paphiopedilum bulllenianum (J) Plocoglotis lowii (K) Spatoglotis kimbaliana (L) Trixpermum amplexicaule

Kunci Determinasi Jenis Anggrek (Orchidaceae) Terestrial yang Didapatkan pada Kawasan Taman Wisata Bukit Kelam, Kabupaten Sintang

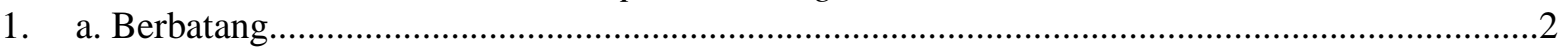

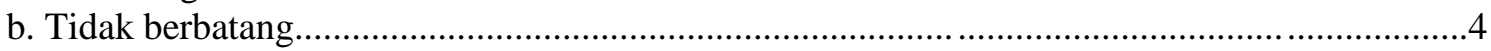

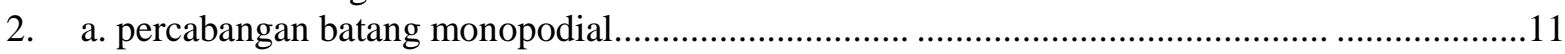

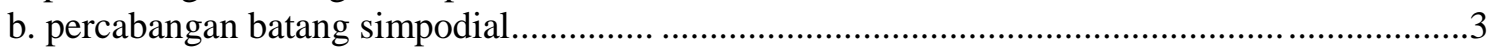

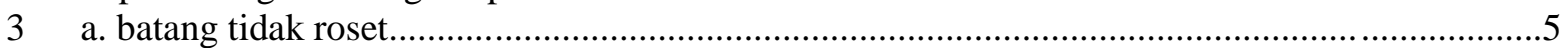

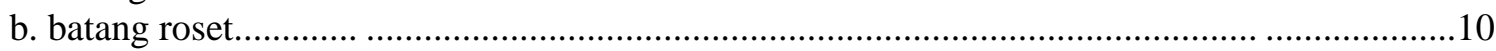

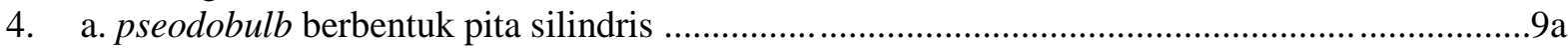

b. psedobulb berbentuk mata lembing (manset)......................................................................

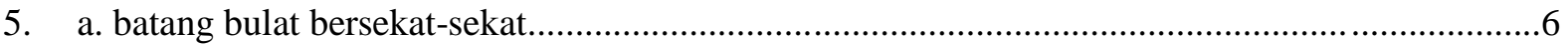

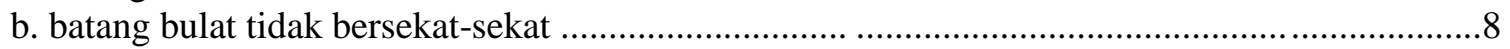

6. a. arah tumbuh batang tegak, batang ditumbuhi rambut-rambut halus.........................................

b. arah tumbuh batang berbaring dan bangun sepal dan tepal lanset, labellum berbentuk bulat telur terbalik bewarna orange.

Liparis sp.

7. a. bentuk batang bulat, bangun daun pita dan bangun sepal jorong, bangun petal sudip, labellum berbentuk bulat telur terbalik bewarna putih, letak lekuk bibir di bagian tengah

Dendrobium lobii

b. bentuk batang segiempat, bangun daun lanset dan bangun sepal segitiga, bangun petal lanset, bagian keping tengah labellum berbentuk bulat bewarna putih. 
8. a.bangun daun pita, pertulangan sejajar dan bangun sepal dan petal jorong, labellum seperti terompet, ujung labellum berbentuk bulat telur berlekuk di tengah............................... Arundina graminifolia

b.bangun daun lanset, pertulangan melengkungbangun sepal dan petal memanjang, keeping tengah labellum memiliki bentuk bulat telur berlekuk di bagian tengah.......................................................................................... Bromheadia finlaysoniana

9. a. bangun daun bulat telur terbalik tumbuh di bagian ujung pseudobulb dan posisi pembungaan berada di ujung pseudobulb dan bunga majemuk, bangun sepal jorong, bangun petal lanset berwarna coklat bening, labellum berbentuk seperti sendok.......................Coelogyne kelamensis

b. bangun daun jorong tumbuh dibagian ujung pseudobulb dan posisi pembungaan berada di sisi pangkal pseudobulb dan bunga majemuk, bangun sepal dorsal memanjang, sepal lateral menggulung bewarna merah, labellum berbentuk bulat dengan ujung meruncing..........................................................................................................Plocoglottis lowii

10. a. bangun daun pita, pertulangan daun sejajar, tipe pembungaan majemuk................................... 12

b.bangun daun lanset, pertulangan melengkung, tipe pembungaan tunggal, dengan labellum menyerupai kantung................................................................... Paphiopedilum bullenianum

11. a.bangun daun jantung, sepal dan petal berbentuk jarum dan labellum berbentuk seperti helm berwarna marun.

Corybas pictus

b.bangun daun memanjang (oblongus) dan bangun sepal dan petal oblongus, labellum seperti kantong yang berukuran kecil bewarna putih keunguan...... amplexicaule

Thrixspermum

12. a.bangun sepal bulat telur terbalik, bangun petal sudip, labellum berbentuk jorong berlekuk pada bagian tengah.

Dipodium pictum

b. bangun sepal dan petal jorong, keping sisi labellum seperti martil, keeping tengah seperti persegi lima berwarna kuning Spathoglottis kimballiana

\section{Pembahasan}

Orchidaceae yang ditemukan pada kawasan Taman Wisata Alam Bukit Kelam Kabupaten Sintang, sebanyak 12 spesies yang termasuk ke dalam 11 genus yaitu, Arundina graminifolia, Bromheadia finlaysoniana, Corybas pictus, Coelogyne kelamensis, Dendrobium lobii, Dendrobium olivaceum, Dipodium pictum, Liparis sp., Paphiopedilum bullenianum, Plocoglottis lowii, Spathoglottis kimballiana, Thrixspermum amplexicaule ( Tabel 1).

Arundina graminifolia yang ditemukan memiliki ciri khusus dengan batang seperti bambu, batang bulat tegak lurus. Chan et al., 1994 menyebutkan bahwa Arundina diambil dari kata "Arundo" yang berarti pembuluh atau seperti bambu, hal ini dikarenakan genus dari tumbuhan anggrek ini dicirikan sebagai tumbuhan terestrial yang sepintas daunnya menyerupai rerumputan dan batangnya menyerupai bambu. Namun ada hal yang membedakan tumbuhan ini dengan rerumputan dan bambu yaitu bagian batangnya. Bagian batang rumput memiliki rongga sedangkan pada Arundina bagian batang pejal atau solid. Genus dari tumbuhan anggrek ini secara umum tersebar di wilayah Asia Selatan dan Asia
Tenggara mulai dari india, Sri Lanka, Cina, Taiwan, Indonesia, malaysia, dan umumnya di pulau-pulau pasifik (Chan et al., 1994).

Bromheadia yang ditemukan di kawasan TWA Bukit Kelam adalah jenis Bromheadia finlaysoniana. Jenis anggrek ini memiliki batang berbentuk bulat (teres), bersekat-sekat, arah tumbuh batang tegak lurus (erectus), daun (lamina) yang memiliki bentuk lanset (lanseolatus), ujung daun membulat (rotundatus), tepi daun rata (integer). Sepal dan petal memiliki bentuk memanjang (oblongus), bagian ujung meruncing (acuminatus), tepian rata (integer). Permukaan helaian sepal dan petal bewarna putih. Nama genus Bromheadia digunakan untuk menghormati Edward Bromhead yang melakukan penelitian tentang afinitas alami tumbuhan dan dikenal sebagai botanis yang sistematis (Lindley, 1841 dalam Teoh, 2016).

Nama epitet "finlaysoniana" adalah nama khusus yang diberikan untuk menghormati George Finlayson yang mengumpulkan spesimen jenis ini (Wiart, 2012). Jenis $B$. finlaysoniana juga ditemukan di daerah Taman Wisata Alam Baning, Hutan Mengkusai, dan 
Hutan Adat Kantuk Kabupaten Sintang (Ariyanti, 2008) dan di Hutan Alam Desa Beginjan Tayan Hilir, Kabupaten Sanggau.

Corybas yang ditemukan memiliki ciri khusus yaitu labellum seperti helm. Xinqi et al., 2009 menyebutkan bahwa Corybas dicirikan sebagai tumbuhan yang memiliki bagian umbi yang tersimpan dibawah permukaan tanah dengan perakaran serabut, batang pendek yang hanya terdiri atas daun tunggal yang memiliki bangun jantung (cordatus). Letak pembungaan di bagian terminal dan tipe pembungaan tunggal. Bagian bunga didominasi oleh sepal dorsal yang berukuran besar dan labellum dengan variasi warna beranekaragaman. Nama genus Corybas berasal dari bahasa Yunani "koribas" yang mengacu kepada labellum yang berbentuk seperti helm (Chan et al., 1994). Jenis anggrek dari genus Corybas yang didapatkan dikawasan TWA Bukit Kelam adalah jenis $C$. pictus. Nama epitet "pictus" berasal dar kata Yunani "picta atau pictum" yang berarti "sesuatu yang bewarna cerah, yang dihias menggunakan warna atau di cat" yang merujuk pada warna variegasi daun dan bunga jenis anggrek ini (Gledhill, 2008).

Coelogyne yang ditemukan memiliki sepal dan petal berwarna coklat bening. Lindley, 1825 dalam Chan et.al., 1994 menggambarkan arti nama genus Coelogyne dari bahasa yunani "koilos" yang berarti "berongga" dan "gyne" ang berarti "perempuan", hal ini merujuk pada bentuk stigma (kepala putik) yang cekung dan berongga (Gravendeel \& Vogel, 2002). Jenis anggrek dari genus Coelogyne yang didapatkan dikawasan TWA Bukit Kelam adalah jenis $C$. kelamensis. Nama epitet "kelamensis" merujuk kepada tempat ditemukan jenis ini pertama kali di bukit Kelam Kabupaten Sintang (Chan et.al., 1994), Kalimantan Barat. Jenis anggrek ini dicirikan memiliki sepal dorsal dan lateral berbentuk jorong (ellipticus) bewarna coklat bening dengan ujung sepal tumpul (obtusus). Petal memiliki bentuk pita lurus (linearis) dengan ujung runcing bewarna coklat bening dan penampang penampang melintang berbentuk rata.

Dendrobium adalah genus dari sekitar 1200 jenis anggrek dalam famili Orchidaceae. Dendrobium berasal dari dua kata Yunani "dendron" yang berarti pohon dan "bios" yang berarti kehidupan, merujuk pada kebiasaan epipit kebanyakan jenis dari genus ini (Teoh, 2016). Dendrobium memiliki pola pertumbuhan simpodial dan monopodial. Genus Dendrobium memiliki keragaman yang besar, baik habitat, ukuran, bentuk pseudobulb, daun, serta bentuk dan variasi warna bunga yang beragam (Chan et al., 1994). Jenis anggrek dari genus Dendrobium yang didapatkan dikawasan TWA Bukit Kelam adalah jenis Dendrobium lobbii dan Dendrobium olivaceum. Nama epitet "lobbii" digunakan untuk menghormati Thomas Lobb yang mengumpulkan spesimen ini (Mayr,1998). Menurut Chan et al (1994) nama epitet "olivaceum" yang berarti olive green atau hijau zaitun, mengacu pada warna sepal dan petal jenis ini yang memiliki warna hijau dan oranye tua.

Dipodium yang ditemukan dengan tipe bunga majemuk kebanyakan jenis adalah racemus (tandan), sepal dan dorsal terletak saling lepas dan bentuknya hampir mirip satu sama lain. Nama genus Dipodium berasal dari kata Yunani "Di" yang berarti "dua" dan "podia" yang berarti "kaki kecil", kata ini merujuk pada dua kaki kecil yang menyokong polonia (Teoh, 2016). Jenis anggrek dari genus Dipodium yang didapatkan dikawasan TWA Bukit Kelam adalah jenis $D$. pictum. Nama epitet pictum berasal dari kata Yunani "picta" yang berarti "sesuatu yang bewarna cerah, yang dihias menggunakan warna atau di cat" merujuk pada variegasi warna bunga $D$. pictum di bagian sepal dan petal yang bewarna dasar putih terdapat bercak-bercak warna ping (Gledhill, 2008)

Liparis yang didapatkan dikawasan TWA Bukit Kelam adalah jenis Liparis sp. Jenis anggrek yang ditemukan ini cirikan memiliki Batang berbentuk bulat (teres), daun hanya terdiri atas lembar daun (lamina) dan upih daun (vagina) dengan susunan daun rangkap saling berhadapan. Helaian daun memiliki bentuk jorong (ellipticus). Posisi pembungaan berada diantara dua ketiak daun (flos lateralis) dengan tipe pembungaan majemuk berbatas bersifat monochasial. Perhiasan bunga terdiri atas 3 sepal, 2 petal, dan 1 labellum. Labellum memiliki bentuk bulat telur terbalik (obovatus), permukaan labellum bagian atas bewarna 
orange tua dan bagian bawah bewarna orange muda.

Paphiopedilum yang ditemukan dengan ciri labellum berbentuk kantung/selop. Kelompok anggrek dari genus ini umumnya bersifat epifit, beberapa jenis bersifat litofit dan terestrial, batang simpodial, tidak memiliki pseudobulb, umumnya daun roset berbentuk bulat telur, jorong, sempit, dan biasanay memiliki pola belang belang, bentuk bunga khas pada bagian labellum seperti bentuk kantong (Chan et al., 2016). Menurut Braem et.al, 2016 nama genus Paphiopedilum memiliki arti lady slipper atau Venus slipper (sandal wanita) yang berasal dari kata "Paphos" sebuah nama kuil di kota di Siprus, tempat suci bagi Aphrodite (salah satu dewa dalam kepercayaan Yunani kuno) dan "pedilon" dari bahasa yunani yang berarti "sandal" yang merujuk pada bentuk bibir (labellum) dari bunganya yang seperti kantong menyerupai sendal wanita. Jenis anggrek dari genus Paphiopedilum yang ditemukan di kawasan TWA Bukit kelam dalam penelitian ini adalah jenis Paphiopedilum bullenianum. Nama epitet "bullenianum" berasal dari nama Bullen yang merupakan seorang holtikultura berkebangsaan inggris (Bullen is the grower for Messrs) (Braem et.al, 2016).

Plocoglottis yang ditemukan pada penelitian ini memiliki ciri yaitu dua sepal lateral pada bunga $P$. lowii menggulung menampakan sisi permukaan bawah sepal lateral yang bewarna merah marun yang ditumbuhi rambut-rambut halus bewarna bening. Quattrocchi, 2012 menyatakan bahwa nama genus Plocoglottis berasal dari bahasa Yunani "ploke" yang berati "anyaman" dan "glottis" yang berarti "lidah" merujuk pada bentuk labellum bunga yang memiliki mekanisme pegas yang membantu proses penyerbukan ketika bunga baru terbuka. Jenis anggrek dari genus Plocoglottis yang ditemukan di kawasan TWA Bukit kelam dalam penelitian ini adalah jenis Plocoglottis lowii. Nama epitet "lowii" digunakan untuk menghormati Sir Hug Low (1824-1905) yang merupakan seorang seorang administrator dan naturalis berkebangsaan inggris (Braem et.al, 2016).

Spathoglottis yang ditemukan pada penelitian ini dicirikan memiliki sepal dorsal, sepal lateralis dan petal memiliki bentuk jorong (ellipticus), ujung runcing (acutus), tepi rata (integer) dan penampang melintang masingmasing bagian sepal dan petal berbentuk cembung. Permukaan helaian bagian atas dan bawah pada sepal dan petal memiliki warna kuning. Labellum terdiri atas keping sisi, keping tengah, dan kalus. Nama genus Spathoglottis berasal dari kata Yunani yaitu "spathe" yang berarti "sendok atau spatula" seperti sendok untuk mengaduk dan mencampur atau seperti batang daun palem yang merujuk pada "bentuk batang dan helaian" dari daun genus ini. glottis yang berarti "lidah" yang mengacu pada lobus tengah yang luas dari labellum (Teoh, 2016).

Thrixspermum yang ditemukan dalam penelitian ini memiliki ciri seluruh bagian bunga berwarna ungu muda dangan rambut halus. Anggrek dalam genus ini hidup epifit, litopit, dan terestial, permukaan helaian daun kasar, bunga berumur pendek dengan sepal dan petal memiliki bentuk yang hampir mirip satu sama lain (Jones, 2006). Nama genus Thrixspermum berasal dari kata Yunani "thrix, trichos" yang berarti "rambut" dan "sperma" yang berarti "benih" mengacu pada bentuk buahnya seperti kapsul dan memiliki rambutrambut halus (Quattrocchi, 2012). Jenis anggrek dari genus Thrixspermum yang ditemukan di kawasan TWA Bukit kelam dalam penelitian ini adalah jenis Thrisxspermum amplexicaule. Nama epitet "amplexicaule" berasal dari kata Yunani "amplexus" yang berarti "menggenggam" dan "caulis" yang berarti "batang" merujuk pada posisi duduk daun jenis T. amplexicaule yang memeluk batang (Quattrocchi, 2012).

\section{DAFTAR PUSTAKA}

Aryanti E.E..2008 Inventarisasi Anggrek di kabupaten sintang, Kalimantan Barat. Jurnal Biodervisitas

Balai Konservasi Sumber Daya Alam Kalimantan Barat, 2010, Informasi kawasan Konservasi Kalimantan Barat

Braem, G, Chiron, G, \& Ohlund, S, 2016, The Genus Paphiopedilum 2nd Edition, Bishen Singh Mahendra Pal Singh \& Moorland eBooks 
Chan, C, L, Lamb, A, Shim, P, S, \& Wood, J, J, 1994, Orchid of Borneo: Vol. 1 Indroduction and A Selection of Species, The Sabah Society, Kinabalu

Cribb, P, 1997, Slipper Orchid of Borneo. Natural History Publication. Kinibalu

Gunadi, T, 1985, Anggrek dari Вепиа ke Benua, Penerbit Angkasa, Bandung

Gledhill, D, 2008, The Names of Plant: Fourth Editon, Cambridge University Press, New York

Gravendeel \& Vogel, 2002,' Revision of Coelogyne section Moniliformes (Orchidaceae) Based on Morphology, Plastid and nrDNA ITS Sequences', Blumea, vol. 47, no. 3

Irawati, 2002, 'Pelestarian jenis anggrek di Indonesia', Proseding Seminar Anggrek Nasional, Yogyakarta

Jones, D, L, 2006, A Complete Guide to Native Orchids of Australia Including the Island Terriories, French Forest, New Holland
Mayr, H, 1998, Orchid Name and Their Meaning, Lutbrech \& Cramer Ltd, New York

Quattrocchi, U, 2012, CRC world Dictionary of Medical and Poisonous Plants: Names, Scientifik Names, Eponyms, Synonym, And Etymology (5 Volume Set), CRC press Taylor \& Francis Group, Florida

Siregar, C, Listiawati, A, \& Purwaningsih, 2005, Anggrek Spesies Kalimantan Barat Vol. 1. Pontianak, Lembaga Penelitian dan Pengembangan Pariwisata Kalimantan Barat (LP3KB)

Teoh, E, S, 2016, Medicinal Orchids of Asia, Springer International Publishing S, New York

Wiart, C, 2012, Medical Plant of China, Korea, and Japan: Bioresources for Tomorrow's Drugs and Cosmetic, Boca Raton, Florida

Xinqi, C, Ormerod, \& Wood, J, J, 2009, 'Glossary of botanical Terms Used in the Orchidaceae', Flora of China, vol. 25. hal. 211-212 